\title{
¿Confinados en la Arcadia y desconfinados en la corte? Una aproximación a la estructura de los relatos cortesanos en las novelas pastoriles (con una nota sobre Darinto en La Galatea) \\ Confined in the Arcadia an Unconfined in Court? An Approximation to the Structure of Courtly Stories in Pastoral Novel (with a Note about Darinto in La Galatea)
}

\section{Sara Santa-Aguilar}

https://orcid.org/0000-0002-3199-6504

Universidad de La Rioja

ESPAÑA

sara-isabel.santa@unirioja.es

[Hipogrifo, (issn: 2328-1308), 9.2, 2021, pp. 389-398]

Recibido: 15-02-2021 / Aceptado: 18-03-2021

DOI: http://dx.doi.org/10.13035/H.2021.09.02.29

Resumen. Un ingrediente invariable de las novelas pastoriles son las historias de cortesanos que, movidos por una desgracia, migran al campo. Estos personajes encuentran la solución a sus problemas en la Arcadia. Sin embargo, este espacio no es para ellos un lugar donde puedan permanecer indefinidamente viviendo un Beatus ille. Parte fundamental de la estructura de final feliz de estas novelas es la restitución de estos personajes a sus lugares de proveniencia. El presente artículo analizará esta fórmula genérica, la contrastará con la propuesta de Cervantes en La Galatea y planteará un paralelo con las formas de interacción entre ciudad y campo que se han derivado del confinamiento al que llevó la pandemia en 2020.

Palabras clave. Novela pastoril; cortesanos; La Galatea; Darinto. 
Abstract. The stories of courtiers who migrate to the countryside moved by misfortune are an invariable ingredient of Pastoral Novel. These characters find the solution to their problems in the Arcadia. Nevertheless, this space is not for them a place to indefinitely stay, living a Beatus ille. A fundamental part of the happy ending structure of these novels is the restitution of these characters to their places of provenience. This article will propose an analysis of this structure, contrast it with Cervantes' proposal in La Galatea and draw a parallel with the forms of interaction between city and countryside that resulted from the confinement to which the pandemic led in 2020.

Keywords. Pastoral Novel; Courtiers; La Galatea; Darinto.

Después de la extraña experiencia del 2020, inevitablemente la palabra confinamiento evoca espacios públicos restringidos, locales cerrados y parques infantiles precintados. Confinados fuimos testigos desde las ventanas de nuestras casas -y sobre todo desde las de nuestros buscadores de Internet- de cómo nuestro "afuera" más inmediato se hacía ajeno a nuestro ámbito de experiencia cotidiana y se poblaba de seres que habían cruzado el límite que los separaba de nuestros perímetros urbanizados. Un puma bajaba de las montañas en Santiago de Chile, las cabras paseaban por Gales, los jabalíes recorrían las calles de Barcelona e incluso un zorro fue visto en Bogotá. Globalmente, los huidizos habitantes de los entornos naturales poblaron las ciudades, mientras la gran mayoría de los habitantes de las ciudades nos atrincherábamos en nuestros domicilios. Sin embargo, ante unos espacios urbanos vedados o limitados, los habitantes de la ciudad que tuvieron la posibilidad de hacerlo no dudaron en migrar al campo. En España, por ejemplo, se verificó una marcada tendencia entre quienes contaban con una segunda residencia a pasar el confinamiento lejos de las grandes urbes y en países como Alemania, donde los paseos a entornos rurales no sufrieron restricciones, estos espacios se configuraron como el lugar de esparcimiento por excelencia de los citadinos.

Planteada de esta manera, esta situación ofrece varios paralelos con la estructura de las novelas pastoriles, donde el límite entre corte y aldea y, sobre todo, las alteraciones de este hasta la final vuelta a la "normalidad" son una fórmula genérica.

\section{TRAMAS DE QUIEBRA Y RECOMPOSICIÓN DEL LÍMITE}

Como bien anota John T. Cull, alrededor de la literatura pastoril orbita el prejuicio según el cual esta se limita a plasmar un edulcorado mundo ideal, ajeno a todo lo que pueda estar fuera del formulístico locus amoenus primaveral con sus consabidas fuentes y pájaros cantores ${ }^{\top}$. No poca culpa tuvo Cervantes en legar esta imagen a la posteridad, pues, aunque como gran conocedor del género explota todas sus complejidades y matices en La Galatea, lo utiliza continuamente en su 
obra posterior para subrayar el abismo entre la "ficción" y la "realidad". Baste recordar la conocidísima presentación que hace Berganza de sus amos pastores en El coloquio de los perros:

Digo que todos los pensamientos que he dicho, y muchos más, me causaron ver los diferentes tratos y ejercicios que mis pastores y todos los demás de aquella marina tenían de aquellos que había oído leer que tenían los pastores de los libros; porque si los míos cantaban, no eran canciones acordadas y bien compuestas, sino un «Cata, lobo, do va Juanica» y otras cosas semejantes; y esto no al son de chirumbelas, rabeles o gaitas, sino al que hacía el dar un cayado con otro o al de algunas tejuelas puestas entre los dedos; y no con voces delicadas, sonoras y admirables, sino con voces roncas, que, solas o juntas, parecía, no que cantaban, sino que gritaban, o gruñían. Lo más del día se la pasaban espulgándose o remendando sus abarcas; ni entre ellos se nombraban Amarilis, Fílidas, Galateas y Dianas, ni había Lisardos, Lausos, Jacintos ni Riselos; todos eran Antones, Domingos, Pablos o Llorentes, por donde vine a entender lo que pienso que deben creer todos: que todos aquellos libros son cosas soñadas y bien escritas para entretenimiento de los ociosos, y no verdad alguna; que a serlo, entre mis pastores hubiera alguna reliquia de aquella felicísima vida, y de aquellos amenos prados, espaciosas selvas, sagrados montes, hermosos jardines, arroyos claros y cristalinas fuentes, y de aquellos tan honestos cuanto bien declarados requiebros, y de aquel desmayarse aquí el pastor, allí la pastora, acullá resonar la zampoña del uno, acá el caramillo del otro².

Sin embargo, esta tajante oposición entre "real" e "imaginario" que plantea Berganza en su reflexión debe ser matizada a la luz de las estructuras de las mismas novelas pastoriles.

En primer lugar, cabe señalar la convención de presentar personajes históricos bajo nombres de pastores -a la que se refieren explícitamente Montemayor en el prólogo de la Diana y el mismo Cervantes en el de La Galatea-, la cual, como sostiene Dominick Finello, desde un principio «apunta marcadamente a la destrucción de la frontera entre el mundo real y el mundo imaginario»3. Pero más allá del motivo de los personajes reales con nombres fingidos, si volvemos la mirada hacia los tópicos poéticos que están en la raíz misma de la literatura bucólica, nos encontramos con el motivo del menosprecio de corte y alabanza de aldea. Se alaba la vida sencilla del pastor por oposición a la opulencia cortesana. Solo a nivel de alusiones textuales, hay ya una convivencia de ambos mundos en el corazón del género.

Además, centrándonos ya en la novela pastoril específicamente, es de notar que la corte tiene cabida en el mismo universo ficcional de los pastores literarios. En palabras de Cull, «though the city is exiled from the pastoral pleasance, it is

2. Cervantes, Novelas ejemplares, II, p. 309.

3. Finello, 2005, p. 106. De hecho, justamente esta característica de la literatura pastoril llevó a Sevilla Arroyo y a Rey Hazas a explicar por qué Cervantes se inicia en el género pastoril: «la bucólica era, así, el marco adecuado para la unión de vida y literatura, o para la literaturización de la vida real, o para presentar como ficticio lo que era auténtico, y al revés, para dar rango de vida a lo que no pasaba de mera ficción pastoril» (1996, p. X). 
always lurking just beyond the periphery of the confines of the garden» ${ }^{4}$. Corte $y$ aldea colindan, los cortesanos migran a la Arcadia y desde allí enuncian sus Beatus ille, que, en el marco ficcional de este género narrativo, no son otra cosa que una comparación entre sus experiencias en la corte y sus deslumbradas impresiones de citadinos sobre la Arcadia. Emblemático al respecto resulta el Beatus del cortesano Darinto, quien, tras departir con los cordiales pastores de La Galatea, confiesa a Timbrio:

Veo con cuánta curiosidad vos y yo (y los que siguen el trato nuestro) procuramos adornar las personas, sustentar los cuerpos y aumentar las haciendas, y cuán poco viene a lucirnos, pues la púrpura, el oro, el brocado (que sobre nuestros cuerpos echamos), como los rostros están marchitos de los mal digeridos manjares, comidos a deshoras, y tan costosos como mal gastados, ninguna cosa nos adornan ni pulen ni son parte para que más bien parezcamos a los ojos de quien nos mira; todo lo cual puedes ver diferente en los que siguen el rústico ejercicio del campo, haciendo experiencia en los que tienes delante, los cuales podría ser, y aun es así, que se hubiesen sustentado y sustentan de manjares simples y en todo contrarios de la vana compostura de los nuestros. Y, con todo eso, mira el moreno de sus rostros, que promete más entera salud que la blancura quebrantada de los nuestros; y cuán bien les está a sus robustos y sueltos miembros un pellico de blanca lana, una caperuza parda y unas antiparras de cualquier color que sean. Y con esto a los ojos de sus pastoras deben de parecer más hermosos que los bizarros cortesanos a los de las retiradas damas. ¿Qué te diría, pues, si quisiese, de la sencillez de su vida, de la llaneza de su condición y de la honestidad de sus amores? No te digo más, sino que conmigo puede tanto lo que de la vida pastoral conozco, que de buena gana trocaría la mía con ella 5 .

En las novelas pastoriles es recurrente que los cortesanos irrumpan en el locus amoenus de los pastores literarios. Sin embargo, es de notar que esta trasgresión del límite entre la corte y la Arcadia no está motivada por el tópico de la alabanza de aldea y menosprecio de corte - que llega más bien como consecuencia, pero rara vez como causa de sus desplazamientos-, sino por una crisis.

En La Diana de Montemayor, la cortesana Felismena toma el hábito de pastora para buscar a don Felis, su amado. En la Diana enamorada de Gil Polo, de Alcida y Marcelio, su enamorado y hermano de Felismena, se revela que son pastores disfrazados, cortesanos que, después de muchas desventuras que obstaculizan su matrimonio, terminan en dicho hábito: ella, huyendo de su prometido, y él intentando recobrarla. En El pastor de Fílida, Alfeo es un cortesano que, movido por un dolor que considera irreparable, decide acabar sus días lejos de la corte vestido de pastor, y tras del cual sale Andria, su enamorada, vestida igualmente de pastora. También Cervantes retoma esta estructura en La Galatea a través del personaje de Silerio, un cortesano que entra a la Arcadia para acabar sus días como ermitaño 
creyéndose culpable de la muerte de Nísida -la amada de su amigo Timbrio, de quien él también está enamorado-. Buscando a Silerio para desengañarlo, entran Timbrio, Nísida y Blanca, acompañados por Darinto.

Buscar al amado, huir del amante o el deseo de acabar los días auto expatriados a causa de un dolor irreparable que anula el deseo de la vida en sociedad son las razones que llevan a los cortesanos a entrar al mundo de los pastores en este género literario. La Arcadia no es a priori un ideal para los cortesanos. Es Cervantes quien, además de volver sobre la tradicional trama de emigración forzosa de los cortesanos desdichados ${ }^{6}-y$ aprovechando justamente la posibilidad de tránsito de sobre la que se erige esta estructura- decide poblar sus loci amoeni de "Quijotes de la bucólica", personajes que acogen la vida pastoril por sí misma, movidos por tópicos literarios, como es el caso de Lauso y Lenio en La Galatea o Rutilio en el Persiles, sin olvidar los proyectos pastoriles del mismo don Quijote o a los integrantes de la fingida Arcadia de la segunda parte de su opera magna.

No obstante, aunque la Arcadia no sea en sí misma lo que motiva el desplazamiento en estas tramas pastoriles, es allí donde las peripecias de los cortesanos llegan invariablemente a feliz término, entre otras cosas, porque estos loci amoeni - con excepción de La Galatea- albergan seres sobrenaturales que solucionan los conflictos, como la sabia Felicia en las dos Dianas o el mago Erión en El pastor de Fílida, herederos sin duda del mago Severo de las églogas de Garcilaso. Estos personajes se encargarán de que el buscador y el buscado se reúnan, de que se restablezca el amor entre las parejas y se aclaren los malentendidos que originan sus rupturas y, de ser necesario, administran también brebajes del amor o del olvido, con los que garantizan el fin del sufrimiento cuando las intrigas y triángulos amorosos de estas tramas no se pueden solucionar con los ingredientes mismos que las constituyen.

Una vez resueltas las inquietudes amorosas, los cortesanos vuelven a la corte, que no necesariamente se presenta como un ámbito de corrupción que contrasta con la pureza del campo, como en los tópicos poéticos, sino que puede mostrarse también como un mundo de refinamiento al que pertenecen algunos personajes? ${ }^{7}$.

6. Nótese que la historia de Timbrio y Silerio no es la única que sigue esta estructura, sino que se trata de una fórmula recurrente en la narrativa posterior del alcalaíno. En el Quijote, Cardenio entra también con la intención de acabar sus días presa de un doloroso malentendido y Grisóstomo se viste de pastor para seguir a la bella Marcela, que tampoco es una pastora, sino que ha tomado ese hábito para ejercer su libertad. A estas historias se suma, en el Persiles, la historia de Renato y Eusebia, cortesanos que, tras una historia de amor, honor, duelos y calumnias, terminan viviendo como ermitaños. Muñoz Sánchez en su estudio de esta historia resalta justamente que la vida idílicamente presentada de estos dos personajes no ha sido escogida «en y por sí misma» (2008, p. 218). Para un análisis detallado de la estructura de esta trama remito a su artículo completo.

7. La corte como lugar de refinamiento también es un tópico que suele ser traído a colación en la caracterización de los personajes. Para destacar el ingenio de los pastores se suele afirmar que «parecen salidos de la corte». En La Diana de Montemayor la sabia Felicia califica las preguntas de Siralvo como «más que de pastor» (p. 297), en la de Gil Polo el entendimiento de Diana también pasa por cortesano (p. 153), e incluso la primera presentación de Galatea retoma ese motivo y lo hiperboliza, pues el entendimiento de la pastora cervantina no solo puede ser equiparado al de las cortesanas, sino que lo supera: 
Parte del restablecimiento del orden y feliz desenlace en la lógica de las novelas pastoriles es justamente la vuelta de los personajes a su lugar de proveniencia. Si bien es cierto que en estas novelas no estamos ante el tópico caballeresco del jardín como laberinto ${ }^{8}$ y no hay ninguna barrera material ni mágica que impida salir de allí a los personajes, su presencia en el espacio arcádico es, como los dolores que la motivan, una pieza fuera de lugar, en definitiva, algo que pide "solución". Felicidad y regreso son elementos que se conjugan en la idea de orden que rige la estructura de final feliz en este género literario.

El caso de Alcida y Marcelio en la Diana de Gil Polo resulta particularmente elocuente, pues la sabia Felicia, como parte de su rol de agente solucionador, les pide a los cortesanos que cambien su atuendo de pastores una vez resueltas sus inquietudes amorosas. Dice una de las ninfas:

La sabia Felicia me envía [...] para que vengáis conmigo al ameno jardín donde tiene que hablaros. Mas conviene que tú, Marcelio, dejes el hábito de pastor y te vistas estas ropas que aquí traigo, a tu estado pertenecientes [...]. Tomó entonces Aretea de las manos de otra ninfa que con ella venía las ropas que Marcelio había de ponerse, y de su mano le ayudó a vestirlas, y eran tan ricas y tan guarnecidas de oro y piedras preciosas, que tenían infinito valor ${ }^{9}$.

Alcida aquel día había dejado las ropas de pastora por mandado de Felicia, vistiéndose, aderezándose ricamente, con los vestidos y joyeles que para ello le mandó dar ${ }^{10}$.

Las peripecias cortesanas en las novelas pastoriles presentan una estructura de paso de la dicha a la desdicha para luego volver a la dicha. Se pasa del amor correspondido a un enredo que lleva al desamor, para luego volver al amor correspondido. En definitiva, se trata de estructuras de restitución, en las que la dicha es entendida como volver al punto de partida. Esta estructura implica también una cuestión espacial, una trasgresión de un límite y un regreso.

Solo cuando las inquietudes amorosas de los cortesanos que han pasado a la Arcadia han sido resueltas, estos pueden -y deben- vestir de nuevo sus ropajes y volver a donde les corresponde. Así, la literatura pastoril presenta la forma de un confinamiento en la Arcadia hasta que los problemas no hayan sido solucionados. En definitiva, se trata de unas tramas de vuelta a la "nueva normalidad" que, más allá de la formulística resolución de los conflictos para llegar al consabido final feliz, compromete el restablecimiento de los límites entre corte y Arcadia, entre ciudad y campo, que se han visto alterados.

«fue de tan alto y subido entendimiento que las discretas damas en los reales palacios crecidas y al discreto trato de la corte acostumbradas se tuvieran por dichosas de parecerla en algo, así en la discreción, como en la hermosura» (p. 167).

8. Ver Aguilar-Perdomo 2013 para este tópico.

9. Gil Polo, Diana enamorada, p. 243

10. Gil Polo, Diana enamorada, pp. 246-247. 


\section{LA GALATEA O LA CRISIS DE LA MIRADA INGENUA A LA "NUEVA NORMALIDAD"}

El tratamiento que hace Cervantes en La Galatea de esta, y, podría decirse sin temor a equivocarse, de todas las fórmulas genéricas, merece estudio aparte. Timbrio, Nísida y Blanca se reúnen finalmente con Silerio y, en medio del mundo de los pastores, se acuerda la boda de Timbrio con Nísida y de Silerio con Blanca. Sin embargo, bajo la cáscara de esta estructura, en esta «Blood-spattered Arcadia» ${ }^{11} \mathrm{ca}-$ rente de sabias Felicias, el alcalaíno plantea la historia de un matrimonio sin amor correspondido y de un rechazo sin solución ni paliativos.

Como se resaltó en el acápite anterior, Silerio, Timbrio, Nísida y Blanca entran a la Arcadia por los motivos convencionales: dolor, en el caso del primero, y búsqueda, en el caso de los demás. Además, como sus predecesores, en este espacio parecen encontrar la felicidad para luego regresar a la corte ${ }^{12}$. Sin embargo, el triángulo amoroso solo se rompe externamente: no hay brebajes mágicos ni indicios textuales que apunten a que Silerio haya dejado de amar a Nísida y se haya enamorado de Blanca. Por el contrario, es llamativo que varios personajes tengan que insistir a Silerio que acepte a Blanca por esposa ${ }^{13}$. Comenta el narrador:

Y con esto aconsejó Timbrio a su amigo fuese contento de que Blanca le tuviese, escogiéndola y aceptándola por esposa [...] encareciéndole el gusto y placer que los dos tendrían viéndose con tales hermanas casados. Silerio le respondió que le diese espacio para pensar en aquel hecho, aunque él sabía que al cabo era imposible dejar de hacer lo que él le mandase ${ }^{14}$.

Timbrio también dice a los pastores que:

había de procurar con toda su industria y fuerzas que Silerio viniese en lo que Blanca deseaba, suplicándoles que todos fuesen en ayudar y favorecer su intención [...] quería que todos a Silerio rogasen diese el sí de recibir a Blanca por su legítima esposa ${ }^{15}$.

Consecuentemente con sus deseos, Timbrio y los pastores que lo acompañan determinan «volver a la ermita a rogar a Silerio aceptase a la hermosa Blanca por su esposa» ${ }^{16}, \mathrm{y}$, finalmente, cuando se refiere que los dos personajes se casan, se aclara que Timbrio y Nísida «se lo persuadieron» 17 .

11. Mujica, 1986.

12. Para un estudio de los mecanismos de interpolación a partir de los cuales se relaciona el mundo cortesano y el pastoril en esta historia ver Muñoz Sánchez, 2003.

13. Díaz Ferruz (1990) resalta la incongruencia en el hecho de que Timbrio sea uno de estos personajes que ruegan a Silerio, pues éste había convencido a su amigo de que su amor no era por Nísida sino por Blanca (pp. 299-300). Para una propuesta de reconstrucción del proceso compositivo de esta historia basada en el análisis de estas incongruencias remito a su estudio completo.

14. Cervantes, La Galatea, p. 499-500, énfasis mío.

15. Cervantes, La Galatea, p. 503, énfasis mío.

16. Cervantes, La Galatea, p. 505, énfasis mío.

17. Cervantes, La Galatea, p. 519.

HIPOGRIFO, 9.2, 2021 (pp. 389-398) 
La recurrencia del campo semántico del ruego y la necesidad de una persuasión, al que se opone como patadas de ahogado la petición de tiempo, hasta la final e inevitable subordinación de la propia voluntad a la del amigo que vertebra esta historia, dejan al descubierto las fracturas bajo esta superficie de arquetípico final feliz ${ }^{18}$. Por el lado de Silerio es la historia de un matrimonio sin amor, por el lado de Blanca, es la historia de un amor finalmente aceptado, pero no correspondido. Pero estas no son las únicas gotas de amargura que corroen el armazón de la estructura convencional. En este punto habría que recordar al cortesano Darinto, quien, espejo Blanca, es el otro protagonista de una historia de amor en la que lo máximo a lo que puede aspirar (y que en este caso ni siquiera consigue) es a una resignada aceptación por parte del ser amado.

Darinto guardaba la esperanza de que no encontraran a Silerio para que Blanca se conformara con su amor y accediera a casarse con él: «porque como supo que de ti, Silerio, no se sabía nueva alguna, imaginó que los servicios que él pensaba hacer a Blanca y el tiempo la apartarían de su intención primera; y con esta intención no nos abandonó hasta ayer» ${ }^{19}$. Poca atención se le ha prestado a este personaje en la crítica cervantina. Sin embargo, se trata de una figura sumamente significativa. Darinto recorre en contravía el camino de los cortesanos que entran a la Arcadia en esta tradición literaria. Su entrada no está resortada por una búsqueda y, además, trae como consecuencia una pérdida, que es la que motiva su desconsolada salida, irónicamente seguida por un amanecer poético ${ }^{20}$. Recuérdese, además, que este personaje es la voz que enuncia el Beatus ille, pero termina siendo el único cortesano que en el mundo de los pastores solo encontrará la frustración de sus ilusiones y el desconsuelo irremediable. Su historia es una de esas notas disonantes con las que Cervantes contrapuntea la armonía de la bucólica y sus estructuras convencionales en La Galatea.

También en La Galatea hay trasgresión y restauración del límite, hay ida a la Arcadia y hay regreso, pero la vuelta al punto de partida no necesariamente es en sí misma una solución ni una promesa de felicidad. Los problemas se pueden llevar y traer intactos de esta Arcadia sin dioses y nuevos desgarros pueden surgir en el camino. Si la estructura convencional nos habla de una promesa de feliz y anhelada vuelta a la "nueva normalidad", la aguda mirada cervantina nos advierte de los conflictos que persisten o incluso se agudizan más allá de la recomposición de los límites y de los regresos.

18. Ver Santa-Aguilar, en prensa, para las manifestaciones de esta no correspondencia en el amor en la poesía de navegación amorosa de Silerio.

19. Cervantes, La Galatea, p. 499.

20. Para los usos irónicos de los amaneceres poéticos en La Galatea ver Santa-Aguilar, 2018. 


\section{BiBLIOgRAFÍA}

Aguilar-Perdomo, María del Rosario, «La dualidad de la huerta en el Primaleón», en Palmerín y sus libros: 500 años, ed. Aurelio González, Axayácatl Campos García Rojas, Karla Xiomara Luna Mariscal y Carlos Rubio Pacho, México, El Colegio de México, 2013, pp. 167-190.

Cervantes Saavedra, Miguel de, La Galatea, ed. Francisco López Estrada y María Teresa López García-Berdoy, Madrid, Cátedra, 1999.

Cervantes Saavedra, Miguel de, Novelas ejemplares, ed. Harry Sieber, Madrid, Cátedra, 2007.

Cull, John. T. «Further Observations of Violence in Pastoral Novels», en El tema de la violencia en las literaturas hispánicas. Proceedings of the 10th Annual Conference on Hispanic Literatures at Indiana, ed. Juan Cruz Mendizábal, Indiana (PA), Pennsylvania University Press, 1987a, pp. 58-68.

Cull, John T., «The Curious Reciprocity of Country and City in some Spanish Pastoral Novels», Crítica Hispánica, 9.1-2, 1987b, pp. 159-173.

Díaz Ferruz, Joaquín, «Vacilaciones y contradicciones en la historia de Timbrio y Silerio. Aspectos sobre la composición de La Galatea de Miguel de Cervantes», Glosa. Anuario del Departamento de Filología Española y sus Didácticas, I, 1990, pp. 119-134.

Finello, Dominick, «La Galatea», en Bloom's Modern Critical Views: Miguel de Cervantes, ed. Harold Bloom, Philadelphia, Chelsea House, 2005, pp. 171-189.

Gálvez de Montalvo, Luis, El pastor de Fílida, ed. Miguel Ángel Martínez San Juan, Málaga, Universidad de Málaga, 2006.

Gil Polo, Gaspar, Diana enamorada, ed. Francisco López Estrada, Madrid, Castalia, 1988.

Montemayor, Jorge de, La Diana, ed. Asunción Rallo, Madrid, Cátedra, 1991.

Mujica, Bárbara, «Cervantes' Blood-Spattered Arcadia: La Galatea», en Iberian Pastoral Characters, Potomac, Scripta Humanistica, 1986, pp. 171-209.

Muñoz Sánchez, «Un ejemplo de interpolación cervantina: el episodio de Timbrio y Silerio en La Galatea», Anuario de Estudios Filológicos, XXVI, 2003, pp. 279-297.

Muñoz Sánchez, Juan Ramón, «"Los vírgenes esposos del Persiles": el episodio de Renato y Eusebia», Anales Cervantinos, 40, 2008, pp. 201-224.

Santa-Aguilar, Sara, «La Galatea y las expectativas de una tradición literaria: el caso de Teolinda», Hipogrifo. Revista de literatura y cultura del Siglo de Oro, 6.2, 2018, pp. 283-295. 
Santa-Aguilar, Sara, «"Chè per tal variar natura è bella": variaciones cervantinas sobre el tópico de la navegación amorosa», Anales Cervantinos, 53, en prensa.

Sevilla Arroyo, Florencio, y Rey Hazas, Antonio, «Introducción», en Miguel de Cervantes Saavedra, La Galatea, ed. Florencio Sevilla Arroyo y Antonio Rey Hazas, Madrid, Alianza, 1996, pp. I-LXXXIV. 